\title{
Tata Laksana Hiperglikemia dengan Insulin Tight Controlled di Ruang Intensif Anak
}

Desy Rusmawatiningtyas, Nurnaningsih

Departemen Ilmu Kesehatan Anak Fakultas Kedokteran, Kesehatan Masyarakat, dan Keperawatan Universitas Gadjah Mada/RSUP Dr. Sardjito, Yogyakarta

Latar belakang. Penelitian tata laksana hiperglikemia dengan insulin dan pengaruhnya terhadap keluaran klinis anak sakit kritis belum banyak dilakukan.

Tujuan. Mengetahui keluaran kejadian hipoglikemia, lama rawat inap di ruang intensif, dan angka kematian dalam tata laksana hiperglikemia dengan insulin menggunakan metode tight controlled (gula darah sewaktu/GDS diturunkan sampai kadar 80-120mg/ dL) dan metode permissive controlled (GDS diturunkan sampai $<150 \mathrm{mg} / \mathrm{dL}$ ).

Metode. Menggunakan rancangan uji klinis tak terkontrol dengan randomisasi sederhana. Subyek adalah pasien bukan kasus bedah yang dirawat di Pediatric Intensive Care Unit/PICU RSUP Dr. Sardjito dengan PRISM skor 24 jam pertama $\leq 8$ dan kadar GDS $>150 \mathrm{mg} / \mathrm{dL}$ dalam dua kali pengukuran pada 24 jam pertama perawatan. Subyek dibagi menjadi dua kelompok terapi, yaitu kelompok dengan metode tight controlled dan permissive controlled. Keluaran yang dinilai adalah kejadian hipoglikemia, lama rawat di ruang intensif dan kematian.

Hasil. Lima belas anak masuk dalam kriteria inklusi. Sembilan pasien masuk dalam tight controlled dan 6 pasien dalam permissive controlled. Tidak terdapat keluaran hipoglikemia pada kedua kelompok. Didapatkan $66,7 \%$ subyek meninggal baik pada grup tight

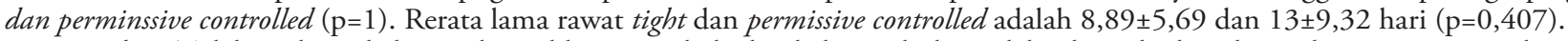

Kesimpulan. Tidak terdapat keluaran hipoglikemia pada kedua kelompok dan tidak ada perbedaan bermakna secara statistik pada mortalitas. Sari Pediatri 2020;21(6):346-51

Kata kunci: tight controlled, hiperglikemia, anak sakit kritis

\section{Tight Controlled Insulin Therapy for Hyperglycemia in Pediatric Intensive Care Unit}

Desy Rusmawatiningtyas, Nurnaningsih

Background. Studies on hyperglycemia management using insulin and its effect on clinical outcomes in critically ill children have not been widely carried out.

Objective. To obtain knowledge regarding the incidence of hypoglycemia, intensive care length of stay/LoS, and mortality in hyperglycemia management with insulin using tight controlled (blood sugar is lowered to $80-120 \mathrm{mg} / \mathrm{dL}$ ) and permissive controlled method (blood sugar is lowered until $<150 \mathrm{mg} / \mathrm{dL}$ ).

Methods. An uncontrolled clinical trial with simple randomization. Subjects were non-surgical patients treated at Pediatric Intensive Care Unit/PICU Dr. Sardjito Hospital with PRISM scores in the first 24 hours $\leq 8$ and blood glucose levels $>150 \mathrm{mg} / \mathrm{dL}$ in two measurements in the first 24 hours. Subjects were divided into 2 therapy groups, tight controlled, and permissive controlled group. We assessed the hypoglycemia incidence, intensive care LoS, and mortality at the end of PICU admission.

Result. Fifteen children were included in the study. Nine patients received tight controlled and 6 patients received permissive controlled treatment. There was no hypoglycemia incidence in both groups. There was $66,7 \%$ death of subjects both in tight and permissive controlled group $(\mathrm{p}=1)$. Mean LoS for the tight and permissive controlled group were 8.89 \pm 5.69 and $13 \pm 9.32$ days $(\mathrm{p}=0.407$ ).

Conclusion. There was no incidence of hypoglycemia in both groups and no statistically significant differences in mortality and LoS. Sari Pediatri 2020;21(6):346-51

Keywords: tight controlled, hyperglycemia, critically ill children

Alamat korespondensi: Desy Rusmawatiningtyas. Departemen Ilmu Kesehatan Anak Fakultas Kedokteran, Kesehatan Masyarakat, dan Keperawatan UGM. Jl. Kesehatan no 1, Sinduadi, Mlati, Sleman, Yogyakarta 55284. Email: desy_rusma@yahoo.co.id 
$\mathrm{P}$ ada keadaan sakit kritis, tubuh mengalami kehilangan kendali terhadap pengaturan glukosa sehingga terjadilah suatu keadaan hiperglikemia. Hiperglikemia dapat disebabkan karena resistensi insulin ataupun defisiensi insulin yang bersifat absolut maupun relatif. ${ }^{1,2}$

Berdasarkan hasil dari penelitian-penelitian terbaru, baik dari populasi dewasa maupun anak membuktikan bahwa keadaan hiperglikemia adalah salah satu penanda dari prognosis kesembuhan yang tidak baik. ${ }^{2,3}$ Pada pasien dengan trauma, stroke, infark miokard atau kelainan akut lainnya, keadaan hiperglikemia meningkatkan morbiditas dan mortalitas. ${ }^{3,4}$ Kondisi hiperglikemia juga menstimulasi suatu kaskade pro-inflamasi, yaitu prothrombosis dan peningkatan stres oksidatif dengan peroksidasi lipid. ${ }^{1}$ Proses tersebut memicu infeksi dengan menurunkan aktivitas fagosit netrofil. ${ }^{2}$

Terapi insulin, berdasarkan beberapa penelitian yang dilakukan pada populasi dewasa, dapat mengatasi efek buruk dari keadaan hiperglikemia dengan efek anti-inflamasi yang poten. ${ }^{2,5}$

Hiperglikemia sering terjadi pada pasien kritis, baik pada dewasa maupun anak, baik pada pasien diabetes maupun bukan diabetes. Penelitian oleh Faustino dan Apkon ${ }^{6}$ pada tahun 2005 mengemukakan kejadian hiperglikemia pada anak kritis non diabetes yang dirawat di PICU berkisar antara 16,7\%-75,0\%. Sementara penelitian Wintergest $\mathrm{dkk}^{7}$ mendapatkan angka kejadian hiperglikemia di PICU sebesar 35,2\%86,7\%. Pada penelitian Nurnaningsih dan Pudjiadi, ${ }^{8}$ didapatkan 33,3\% pasien yang dirawat di PICU RSUP Cipto Mangunkusumo Jakarta memiliki kadar glukosa darah lebih dari $200 \mathrm{mg} / \mathrm{dL}$. Kejadian hiperglikemia pada pasien kritis ini telah dikemukakan pertama kali oleh Claude Bernard ${ }^{9}$ lebih dari seabad yang lalu. Namun sampai saat ini, patofisiologi, pengaruh, dan tata laksana terhadap keadaan tersebut masih menjadi masalah yang diperdebatkan dan menarik untuk diteliti lebih lanjut.

Nilai ambang yang digunakan untuk memulai terapi insulin pada anak sakit kritis dengan hiperglikemia bervariasi antara $110 \mathrm{mg} / \mathrm{dL}$ sampai $>200$ mg/dL. ${ }^{7}$ Di Indonesia, Unit Kelompok Kerja Koordinasi Emergensi dan Rawat Intensif Anak Ikatan Dokter Anak Indonesia merekomendasikan memulai pemberian insulin pada pasien sepsis apabila kadar glukosa darah $\geq 150 \mathrm{mg} / \mathrm{dL} .{ }^{10}$ Namun sampai saat ini, belum ada penelitian maupun rekomendasi batas penurunan glukosa darah yang harus dicapai pada pasien anak dengan sakit kritis.

Pada penelitian ini, kami membandingkan luaran kejadian hipoglikemia, lama rawat di ruang intensif, dan angka mortalitas pada pasien anak sakit kritis non-bedah dalam keadaan hiperglikemia. Pasien ditata laksana dengan titrasi insulin sampai dengan target kadar gula darah $80-120 \mathrm{mg} / \mathrm{dL}$ pada kelompok pertama (metode tight controlled) dan sampai dengan target kadar gula darah $\leq 150 \mathrm{mg} / \mathrm{dL}$ pada kelompok kedua (metode permissive controlled). Kami menggunakan batas hiperglikemia $>150 \mathrm{mg} / \mathrm{dL}$ dan hipoglikemia $\leq 60 \mathrm{mg} / \mathrm{dL}$ sesuai rekomendasi UKK ERIA IDAI $2011 .{ }^{10}$

\section{Metode}

Rancangan penelitian ini adalah uji klinis tak terkontrol dengan randomisasi sederhana menggunakan desain paralel. Pasien dibagi menjadi dua kelompok. Kelompok pertama adalah pasien dengan hiperglikemia $>150 \mathrm{mg} / \mathrm{dL}$ (dengan alat ukur sama) yang terjadi dalam waktu 24 jam pertama perawatan di PICU yang mendapat terapi titrasi insulin sesuai dengan protokol YALE yang sudah dimodifikasi dengan target penurunan gula darah sewaktu sampai $\leq 150$ $\mathrm{mg} / \mathrm{dL}$ (kelompok permissive controlled). Sementara kelompok kedua mendapat terapi insulin dengan target penurunan kadar gula darah sewaktu sampai 80-120 $\mathrm{mg} / \mathrm{dL}$ (kelompok tight controlled).

Populasi penelitian adalah anak sakit kritis non bedah. Populasi terjangkau adalah pasien anak sakit kritis yang dirawat di PICU RSUP Dr. Sardjito Yogyakarta dari 1 Januari 2012 sampai 31 Desember 2012. Sampel yang memenuhi kriteria inklusi dan eksklusi diambil dari populasi terjangkau dengan cara randomisasi sampai besar sampel yang diperlukan terpenuhi sesuai perhitungan.

Kriteria inklusi adalah pasien baru kasus non bedah yang dirawat di PICU RSUP Dr. Sardjito Yogyakarta, berumur antara 1 bulan - 18 tahun dengan PRISM skor $\leq 8$ pada 24 jam pertama perawatan PICU. Kriteria eksklusi adalah (1) pasien yang diketahui memiliki riwayat diabetes melitus atau disertai komorbid Cushing's syndrome (hiperfungsi adrenokortikal), feokromositoma, glukagonoma, dan pankreatitis akut; (2) pasien yang keluar dari PICU atas permintaan sendiri; (3) orang tua tidak bersedia mengikuti penelitian. 
Penelitian ini telah memperoleh kelaikan etik dari Medical and Health Research Ethics Committee (MHREC) Fakultas Kedokteran Universitas Gadjah Mada, Yogyakarta.

Dilakukan pengambilan data yang meliputi usia, jenis kelamin, penggunaan ventilator selama di PICU, penggunaan vasopresor/inotropik, cara pemberian nutrisi, status gizi, lama intervensi, serta kejadian hiperglikemia ulangan dalam 24 jam paska intervensi. Kedua kelompok yang telah mendapat intervensi lalu diikuti dan dilakukan pencatatan untuk kejadian hipoglikemia, luaran kematian, serta lama rawat di PICU.

Data yang diambil tersebut dimasukkan ke dalam komputer dengan program perangkat lunak SPSS 22. Data terkait luaran kematian pada kedua kelompok terapi dianalisis menggunakan uji Fischer karena data tidak memenuhi syarat untuk uji Chi-square. Sementara untuk mencari rerata lama rawat inap pada kedua kelompok, digunakan analisis uji T independen. Tingkat kemaknaan dalam penelitian ini dinyatakan bila $\mathrm{p}<0,05$.

\section{Hasil}

Selama periode pengambilan sampel penelitian dari 1 Januari 2012 - 31 Desember 2012, tercatat terdapat 474 pasien yang dirawat di PICU. Tiga ratus sembilan puluh pasien merupakan kasus non bedah. Kejadian hiperglikemia pada 24 jam pertama ditemukan pada 89 pasien dan 15 pasien yang memenuhi kriteria inklusi dan eksklusi. Subyek penelitian dibagi menjadi dua kelompok, yaitu kelompok dengan nomor rekam medis ganjil mendapat perlakuan terapi dengan tight controlled dan kelompok pasien dengan nomor rekam medis genap mendapat perlakukan terapi dengan permissive controlled. Karakteristik dasar subyek penelitian pada masing-masing kelompok tertera pada Tabel 1. Luaran kematian dan lama rawat di ruang intensif pada dua kelompok terapi tertera pada Tabel 2

Untuk luaran kejadian hipoglikemia saat intervensi terapi insulin, tidak ditemukan satupun kejadian hipoglikemia saat intervensi pada semua subyek penelitian

Tabel 1. Karakteristik subyek penelitian

\begin{tabular}{|c|c|c|}
\hline \multirow{2}{*}{\multicolumn{3}{|c|}{ Kelompok permissive controlled $(\mathrm{n} 2=6)$}} \\
\hline & & \\
\hline Rerata & 36 & 66 \\
\hline \multicolumn{3}{|l|}{ Jenis kelamin } \\
\hline Laki-laki, n (\%) & $3(33,3)$ & $2(33,3)$ \\
\hline \multicolumn{3}{|l|}{ Ventilator } \\
\hline Tanpa, n (\%) & $4(44,4)$ & $1(16,7)$ \\
\hline \multicolumn{3}{|l|}{ Vasopresor/Inotropik } \\
\hline Tanpa, n (\%) & $7(77,8)$ & $4(66,7)$ \\
\hline \multicolumn{3}{|l|}{ Nutrisi } \\
\hline Enteral, n (\%) & $6(66,7)$ & $6(100)$ \\
\hline Parenteral, n (\%) & $3(33,3)$ & $0(0)$ \\
\hline \multicolumn{3}{|l|}{ Status gizi } \\
\hline Gizi baik, n (\%) & $9(100)$ & $6(100)$ \\
\hline \multicolumn{3}{|l|}{ Lama intervensi (jam) } \\
\hline Rerata & 9,4 & 5,0 \\
\hline $\begin{array}{l}\text { Berulangnya hiperglikemia dalam } 24 \\
\text { jam setelah intervensi, } \mathrm{n}(\%)\end{array}$ & $0(0)$ & $2(33,3)$ \\
\hline
\end{tabular}

Tabel 2. Luaran kematian dan lama rawat antara dua kelompok terapi

\begin{tabular}{lccc}
\hline Luaran & $\begin{array}{c}\text { kelompok } \\
\text { tight controlled } \\
(\mathrm{n} 1=9)\end{array}$ & $\begin{array}{c}\text { Kelompok } \\
\text { permissive controlled (n2=6) }\end{array}$ & $\mathrm{p}$ \\
\hline Meninggal & $6(66,7)$ & $4(66,7)$ & $1^{*}$ \\
Lama rawat (hari) & $8,89 \pm 5,69$ & $13 \pm 9,32$ & $0,407^{*}$ \\
\hline
\end{tabular}

${ }^{*} \mathrm{p}<0,05$ (analisis statistik menunjukkan signifikansi) 
Desy Rusmawatiningtyas dkk: Tata laksana hiperglikemia dengan insulin tight controlled di ruang intensif anak

\section{Pembahasan}

Hasil penelitian kami menunjukkan tidak terdapat perbedaan bermakna secara statistik pada luaran kematian. Pada luaran lama rawat di ruang intensif juga tidak terdapat perbedaan bermakna. Untuk kelompok dengan tight controlled, didapatkan lama rawat 8,89 hari, sedangkan untuk kelompok dengan permissive controlled, didapatkan lama rawat 13 hari. Walaupun secara statistik kedua nilai rerata tadi tidak bermakna, tetapi apabila kita melihat risiko yang mungkin terjadi pada pasien saat dirawat di ruang intensif dimana risiko terbesar adalah infeksi nosokomial yang dapat memperburuk keadaan pasien, selisih 4,1 hari dapat dikatakan bermakna.

Hasil penelitian kami tidak dapat membuktikan adanya pengaruh pemberian tata laksana insulin dengan metode tight controlled pada kondisi hiperglikemia yang terjadi dalam 24 jam pertama perawatan pada mortalitas dan lama perawatan pasien kritis di PICU. Hasil ini berlawanan dengan sebagian besar penelitian retrospektif sebelumnya. Hasil penelitian sebelumnya melaporkan bahwa hiperglikemia pada pasien kritis di PICU berhubungan dengan perawatan yang lebih lama dan angka kematian yang tinggi. ${ }^{6,11,12}$ Meskipun menggunakan batasan kadar glukosa darah yang sama dalam mendefinisikan hiperglikemia pada pasien kritis, terdapat beberapa perbedaan karakteristik subyek yang mungkin menyebabkan perbedaan hasil penelitian kami dengan penelitian sebelumnya.

Sejumlah penelitian mengenai hubungan antara hiperglikemia dengan luaran klinis pasien kritis di PICU menunjukkan hasil yang tidak konsisten. Hasil penelitian kami mendukung hasil penelitian Klein $\mathrm{dkk}^{13}$ dan Lodha $\mathrm{dkk}^{14}$ meskipun dengan batasan kadar glukosa darah yang berbeda.

Penelitian terdahulu menunjukkan bahwa batasan kadar glukosa darah merupakan faktor prognosis untuk luaran klinis negatif anak sakit kritis yang berbeda-beda untuk setiap kelompok diagnosis. Risiko kematian meningkat untuk kadar glukosa darah lebih dari 178 $\mathrm{mg} / \mathrm{dL}$ pada anak syok septik, ${ }^{15}$ lebih dari $215 \mathrm{mg} / \mathrm{dL}$ pada bayi yang terdiagnosis enterokolitis nekrotikan, ${ }^{16}$ dan lebih dari $150 \mathrm{mg} / \mathrm{dL}$ pada anak dengan trauma kepala. ${ }^{17}$ Pada penelitian ini dikaji hubungan antara hiperglikemia dengan luaran klinis pada semua pasien PICU tanpa membedakan kelompok diagnosis masing-masing. Perbedaan diagnosis dan batasan kadar glukosa darah yang dipergunakan dapat memengaruhi hasil penelitian. Pada penelitian Krinsley ${ }^{18}$ terhadap pasien dewasa yang dirawat di ICU melaporkan bahwa hubungan antara hiperglikemia dengan mortalitas tergantung pada kelompok diagnosis. Kadar glukosa darah awal berhubungan dengan mortalitas pada kelompok diagnosis bedah, trauma, sepsis, dan jantung, tetapi tidak pada kelompok diagnosis paru atau penyakit medis lainnya.

Hasil studi retrospektif Srinivasan $\mathrm{dkk}^{11}$ melaporkan angka kejadian hiperglikemia dalam 24 jam mencapai $54 \%$ dan kejadian tersebut berkaitan dengan peningkatan risiko mortalitas 3,5 kali lebih tinggi. Durasi hiperglikemia yang lebih panjang dan nilai puncak gula darah yang lebih tinggi selama di PICU berkaitan dengan keluaran yang tidak diinginkan. Kedua hal tersebut berkaitan secara independen dengan mortalitas pada analisis regresi logistik multivariat.

Preissig, $\mathrm{dkk}^{19}$ membentuk sebuah protokol kontrol hiperglikemia di PICU. Gula darah dipertahankan di antara $80-140 \mathrm{mg} / \mathrm{dL}$ menggunakan infus insulin dan ketika dibutuhkan. Didapatkan 51\% anak mengalami hiperglikemia. Sebagian besar pada hari kedua admisi PICU dan diperlukan rerata 5,4 jam untuk mengoreksi hiperglikemia dengan infus insulin. Studi ini menggaris bawahi bahwa kontrol glikemik pada anak sakit kritis, dengan tanpa peningkatan bermakna episode hipoglikemia, dapat dilakukan dengan mudah dan aman.

Studi uji acak terkontrol merupakan studi satusatunya terkait target normoglikemia berdasarkan umur yang menggunakan infus insulin pada pasien anak dan telah dipublikasikan oleh Vlasselaers, dkk. $^{20}$ Tujuh ratus anak yang masuk PICU di Leuven dimasukkan secara acak ke grup dengan insulin intensif (target glukosa $50-80 \mathrm{mg} / \mathrm{dL}$ pada bayi dan $70-100 \mathrm{mg} / \mathrm{dL}$ pada anak) atau grup konvensional (insulin untuk mencegah peningkatan gula darah $>215 \mathrm{mg} / \mathrm{dL}$ ). Intervensi menggunakan insulin intensif menghasilkan durasi rawat inap yang lebih singkat, respon inflamasi lebih rendah yang diindikasikan dengan level CRP pada hari ke-5 dibandingkan dengan data dasar $(\mathrm{p}=0,07)$, dan mortalitas yang lebih rendah (3\% vs. $6 \%$, $\mathrm{P}=0.038$ ). Namun, insiden hipoglikemia didapatkan lebih tinggi pada grup insulin intensif (25\%) dibandingkan dengan grup konvensional $(1 \%){ }^{20}$ Sementara itu, luaran kejadian hipoglikemia selama 
Desy Rusmawatiningtyas dkk: Tata laksana hiperglikemia dengan insulin tight controlled di ruang intensif anak

intervensi sama sekali tidak didapatkan pada kedua kelompok.

Keterbatasan penelitian ini adalah perekrutan pasien yang sulit sehingga sampai batas waktu yang ditentukan besar sampel tidak dapat terpenuhi. Masalah ini banyak terjadi pada penelitian yang melibatkan subyek dengan kelompok pasien sakit kritis. Selain kondisi yang tidak dapat memenuhi kriteria inklusi dan eksklusi juga kesulitan dalam hal melakukan informed consent terhadap orang tua. $\mathrm{Hal}$ ini dapat memengaruhi analisis hasil penelitian dan menurunkan kekuatan penelitian. Penelitian dengan sampel yang lebih besar serta dengan waktu yang lebih lama perlu dilakukan untuk mengkaji lagi bagaimana tata laksana yang lebih baik untuk hiperglikemia pada anak sakit kritis sehingga dapat memperbaiki luaran klinis. Selain itu penelitian yang bersifat multicentre dapat menjadi pilihan mengatasi masalah ini.

\section{Kesimpulan}

Tidak terdapat luaran kejadian hipoglikemia pada kedua kelompok. Tidak ada perbedaan bermakna secara statistik pada luaran mortalitas dan lama rawat pada kedua kelompok penelitian. Meskipun telah terdapat protokol tata laksana hiperglikemia dari PICU di negara maju, tetapi protokol tersebut tidak dapat langsung diterapkan begitu saja karena terdapat perbedaan karakteristik dasar serta spektrum penyakit di negara berkembang dengan negara maju.

\section{Daftar pustaka}

1. Corstjens AM, Van der Horst ICC, Zijlstra JG, dkk. The rate of hypoglycemia: final results of the Glucontrol. Hyperglycemia in critically ill patients: marker or mediator? Intensive Care Med 2007;33:189.

2. Poddar B. Treating hyperglycemia in the critically Ill child: is there enough evidence? Indian Pediatrics 2011;4:531-6

3. Derde S, Vanhorebeek I, Van den Berghe G. Insulin treatment in intensive care patients. Horm Res 2009;71:2-11.

4. Capes SE, Hunt D, Malmberg K, Gerstein HC. Stres hyperglycemia and increased risk of death after myocardial infarction in patients with and without diabetes: a mortality among critically ill patients: a meta-analysis systematic overview. Lancet 2000;355:773-8.
5. Capes SE, Hunt D, Malmberg K, Pathak P, Gerstein HC. Stress hyperglycemia and prognosis of stroke in nondiabetic and diabetic patients: a systematic overview. Variability of blood glucose concentration and short-term. Stroke 2001;32:242632.

6. Faustino EV and Apkon M. Persistent hyperglycemia in critically ill children. J Pediatr 2005;146:30-4.

7. Wintergerst KA, Buckingham B, Gandrud L, Wong BJ, Kache S, Wilson DM. Association of hypoglycemia, hyperglycemia, and glucose variability with morbidity and death in the pediatric intensive care unit. Pediatrics 2006;118:173-9.

8. Nurnaningsih, Pudjiadi A.H. Evaluation of substrate metabolism in critically ill pediatric patients. Berkala Ilmu Kedokt 2008;40:75-80.

9. Van den Berghe, G. How does blood glucose control with insulin save lives in intensive care? J Clin Invest 2004;14:118795.

10. UKK Pediatri Gawat Darurat. Rekomendasi diagnosis dan tata laksana syok septik pada anak. UKK Pediatri Gawat Darurat Ikatan Dokter Anak Indonesia; 2010.

11. Srinivasan V, Spinella PC, Drott HR, Roth CL, Helfaer MA, Nadkarni V. Association of timing, duration, and intensity of hyperglycemia with intensive care unit mortality in critically ill children. Pediatr Crit Care Med 2004;5:329-36.

12. Hirshberg E, Larsen G, Van Duker H. Alterations in glucose homeostasis in pediatric intensive care. Pediatr Crit Care Med 2008;9:361-6.

13. Klein GW, Hoisak JM, Schmeidler J, Rapaport R. Hyperglycemia and outcome in the pediatric intensive care unit. J Peds 2008;153:379-84.

14. Lodha R, Bhutia TD, Kabra SK, Thukra A. Day 1 blood glucose and outcome in critically ill children. Indian pediatrics 2009;46:809-10.

15. Branco RG, Garcia PC, Piva JP, Casartelli CH, Seibel V, Tasker RC. Glucose level and risk of mortality in pediatric septic shock. Pediatr Crit Care Med 2005;6:470-2.

16. Hall NJ, Peters M, Eaton S, Pierro A. Hyperglycemia is associated with increased morbidity and mortality rates in neonates with necrotizing enterocolitis. J Pediatr Surg 2004;39:898-901.

17. Chiaretti A, De Benedictis R, Langer A, dkk. Prognostic implications of hyperglycaemia in paediatric head injury. Childs Nerv Syst 1998;14:455-9.

18. Krinsley JS. Association between hyperglycemia and increased hospital mortality in a heterogenous population of critically ill patients. Mayo Clin Proc 2003;78:1471-8.

19. Preissig CM, Rigby MR. Pediatric critical illness hyperglycemia: risk factor associated with development and severity of hyperglycemia in critically ill children. J Pediatric 
Desy Rusmawatiningtyas dkk: Tata laksana hiperglikemia dengan insulin tight controlled di ruang intensif anak

2009;155:734-9.

20. Vlasselaers D, Milants I, Demet L, dkk. Intensive insulin therapy for patients in paediatric intensive care: a prospective, randomised controlled study. Lancet 2009;373:547-56. 